\begin{tabular}{|c|c|c|c|}
\hline Case Reports $i$ & \multicolumn{2}{|c|}{ Case Rep Gastroenterol 2018;12:608-616 } & \multirow[b]{2}{*}{$\begin{array}{l}\text { Karger } \\
\text { Open access }\end{array}$} \\
\hline Gastroenterology & $\begin{array}{l}\text { DOl: 10.1159/000493921 } \\
\text { Published online: October 17, } 2018\end{array}$ & $\begin{array}{l}\text { (c) } 2018 \text { The Author(s) } \\
\text { Published by S. Karger AG, Basel } \\
\text { www.karger.com/crg }\end{array}$ & \\
\hline & $\begin{array}{l}\text { This article is licensed under the } \\
\text { International License (CC BY-NC) } \\
\text { Usage and distribution for commerci }\end{array}$ & $\begin{array}{l}\text { nons Attribution-NonCommercial } 4.0 \\
\text { ger.com/Services/OpenAccessLicense). } \\
\text { uires written permission. }\end{array}$ & \\
\hline
\end{tabular}

\title{
Anti-TNF Exposure during Pregnancy in Crohn's Disease Patients
}

\author{
Elen Farinelli de Campos Silva ${ }^{a} \quad$ Júlio Pinheiro Baima ${ }^{a}$ \\ Jaqueline Ribeiro de Barros ${ }^{a}$ Fernanda Lofiego Renosto ${ }^{a}$ \\ Carina de Fatima de Sibia ${ }^{b}$ Rogério Saad-Hossne ${ }^{b} \quad$ Ligia Yukie Sassaki $^{a}$ \\ aMedical School, Department of Internal Medicine, São Paulo State University (UNESP), \\ Botucatu, Brazil; b Medical School, Department of Surgery, São Paulo State University \\ (UNESP), Botucatu, Brazil
}

\section{Keywords}

Pregnancy · Anti-TNF therapy · Biological therapy · Crohn's disease · Inflammatory bowel disease

\begin{abstract}
Inflammatory bowel disease (IBD) affects young people of reproductive age. Therefore, a broad discussion is needed about the possible disease effects in pregnancy, as well as the risks of fetal exposure to the medications used, especially biological therapy. This study aimed to describe the management of 4 Crohn's disease patients who received anti-TNF therapy during pregnancy and present a literature review. We reported 4 cases composed of young women who became pregnant while receiving anti-TNF agents. The patients presented a satisfactory response to the clinical treatment and the pregnancies progressed without complications. We did not observe maternal or embryonic toxicity, or unfavorable outcomes. The available data point to inflammatory activity as the main risk factor for unfavorable gestational evolution to date, and showed anti-TNF therapy to be safe during pregnancy and breastfeeding. However, the benefits and risks must be discussed with the patient and management decisions should be taken on an individual basis.

(C) 2018 The Author(s)

Published by S. Karger AG, Basel
\end{abstract}

\section{KARGER}

Ligia Yukie Sassaki

Medical School, Department of Internal Medicine, São Paulo State University (UNESP)

Av. Prof. Mário Rubens Guimarães Montenegro, s/n

Botucatu, SP 18618-970 (Brazil)

E-Mail ligiasassaki@gmail.com 


\section{Case Reports in Gastroenterology}

Case Rep Gastroenterol 2018;12:608-616

DOI: 10.1159/000493921

(c) 2018 The Author(s). Published by S. Karger AG, Basel www.karger.com/crg

Silva et al.: Anti-TNF Exposure during Pregnancy in Crohn's Disease Patients

\section{Introduction}

Inflammatory bowel disease (IBD) is a term used to describe Crohn's disease and ulcerative colitis, characterized by chronic inflammation of the gastrointestinal tract. IBD mainly affects young people of reproductive age [1], therefore, a broad discussion about the disease effect on pregnancy is needed, as well as a discussion about maternal-fetal safety in exposure to the current medications, especially immunobiological agents.

Studies are controversial about the disease effects on fetal growth and development. In general, the health of the baby depends on the type, intensity, and extent of IBD, both before and during pregnancy, as well as depending on the medications used by the mother during gestation [1]. Despite many discussions about the subject, it is suggested that the IBD treatment should be maintained in pregnant patients aiming at reducing the risk of disease activity [1]. There is evidence that the disease activity is more detrimental to gestation and consequently to the fetus than the medical therapy itself [1].

A recent study regarding the use of biological therapy for IBD in pregnant women, carried out in London, showed that anti-TNF therapy is considered to be of low risk and can be used in preconception and during the first two quarters of gestation [2]. Anti-TNF therapy currently available such as etanercept, infliximab, adalimumab, and golimumab is classified as category $B$ by the FDA, indicating that no teratogenic effect has been observed in animal studies, but adequate and controlled safety data in humans are still limited [1]. As mentioned previously, the present study presents 4 case reports of patients exposed to anti-TNF therapy during pregnancy and a literature review on the subject.

\section{Case Reports}

\section{Case 1}

A 30-year-old woman, Caucasian, single, presented with Crohn's disease of ileocolonic extension and fistulizing behavior (Montreal Classification A2, L3, B3), diagnosed in 2004. The patient was treated with combined therapy, receiving azathioprine and infliximab (5 mg/kg) since December 2006. In September 2008, she was admitted to hospital to undergo a perianal abscess drainage. She presented perianal discharge, pain, and discomfort. In March 2009 the infliximab was optimized to $10 \mathrm{mg} / \mathrm{kg}$, aiming at the treatment of ulcerated lesions in the rectum and sigmoid. The patient maintained moderate activity in the sigmoid and rectum as shown by the colonoscopy performed in May 2012. In June 2012, the patient opted for the suspension of all medications due to a 6-week pregnancy (first gestation). After 40 days of medication discontinuation, the patient returned to the emergency room presenting intense abdominal pain, vomiting, diarrhea (20 stools/day), and tenesmus. Laboratory exams showed hematocrit 28.8\%, hemoglobin $9.6 \mathrm{~g} / \mathrm{dL}$, and C-reactive protein (CRP) $4.4 \mathrm{mg} / \mathrm{dL}$. Prednisone $40 \mathrm{mg} /$ day and antibiotic therapy were prescribed. The patient presented significant improvement of symptoms and returned to receiving infliximab $(5 \mathrm{mg} / \mathrm{kg})$. She maintained the biological therapy until the 28th week of gestation, demonstrating adequate disease clinical control. The baby was born at 34 weeks of gestation, by C-section, without complications. The vaccines were postponed for 6 months.

Case 2

A 26-year-old woman, a student, married, was diagnosed with Crohn's disease of ileum involvement (Montreal Classification A2, L1, B2) since October 2007. The colonoscopy 


\section{Case Reports in Gastroenterology}

Case Rep Gastroenterol 2018;12:608-616 DOI: 10.1159/000493921

C 2018 The Author(s). Published by S. Karger AG, Basel www.karger.com/crg

Silva et al.: Anti-TNF Exposure during Pregnancy in Crohn's Disease Patients

performed in July 2007 showed terminal ileum presenting edema, erythema, friability, and ulcers covered by fibrin and ileocecal valve stenosis. Although receiving clinical treatment, having prednisone $1 \mathrm{mg} / \mathrm{kg} /$ day and azathioprine $2 \mathrm{mg} / \mathrm{kg} /$ day, the patient presented recurrent episodes of abdominal pain, abdominal discomfort and distension, malaise, and vomit, as well as weight loss compatible with intestinal subocclusion. She was admitted to hospital and underwent an abdominal computed tomography (CT). The CT showed thickening of intestinal loops and intense blurring of the peritoneal fat in ileal topography. The patient underwent surgery compatible with terminal ileum resection followed by ileo-ascending anastomosis. As postoperative Crohn's disease recurrence prevention, the patient received infliximab $5 \mathrm{mg} / \mathrm{kg}$ combined with azathioprine. A new colonoscopy showed no lesions in the neoterminal ileum or in the ileocolonic anastomosis (Rutgeerts score i0) (Fig. 1). After 6 months of combined therapy, the patient discontinued the use of azathioprine. In October 2011, the patient became pregnant. She maintained the infliximab use during the first two gestation trimesters. The baby was born at term, in good clinical condition, by C-section.

Case 3

A 32-year-old woman, married, a mother of 1 child, was diagnosed with ileocolonic Crohn's disease (Montreal Classification A2, L3, B1) in April 2013. On this occasion, the patient presented an increase in the number of bowel movements, liquid stools with blood and mucus, abdominal pain, and pain in the perianal region. Laboratory exams showed a mild inflammatory process (CRP $1.2 \mathrm{mg} / \mathrm{dL}$, albumin $4.2 \mathrm{~g} / \mathrm{dL}$, hematocrit 38.7\%, hemoglobin $12.8 \mathrm{~g} / \mathrm{dL}$ ). The colonoscopy showed inflammation in the terminal ileum and the presence of erosions in the colon (Fig. 2). She started clinical treatment with mesalazine $3 \mathrm{~g} /$ day, but the medication was changed to azathioprine due to being disease refractory. After 30 days of azathioprine use, the patient presented abdominal pain, nausea, and vomiting, consistent with acute pancreatitis secondary to azathioprine use. The laboratory tests confirmed the diagnosis: amylase $174 \mathrm{U} / \mathrm{L}(30-110)$, lipase $1,621 \mathrm{U} / \mathrm{L}(<300)$, leukocytes $15,100 \times 10^{3} / \mathrm{mm}^{3}$, and serum lactate dehydrogenase $489 \mathrm{U} / \mathrm{L}(<350)$. An abdominal ultrasound was performed, and no changes were seen in the pancreas. The patient was hospitalized and received hospital discharge 7 days later. After 2 months, adalimumab therapy was prescribed for IBD treatment. The patient presented clinical improvement, but maintained active lesions in the colon, evidenced by the colonoscopy performed in June 2014, which showed a linear ulcer in the distal ileum and erosions in the sigmoid and rectum (Fig. 2). In July 2014, the patient returned reporting a 7-week pregnancy. The maintenance of adalimumab was chosen, and the patient remained oligosymptomatic throughout pregnancy, maintaining mild abdominal pain, stool frequency from 3 to 5 times a day, and presence of mucus and blood compatible with mild clinical activity. Moreover, the patient presented mild elevated serum biomarkers, such as CRP $(1.7 \mathrm{mg} / \mathrm{dL})$. Biological therapy was suspended on the 24th week of gestation. The delivery took place in January 2015 by C-section.

\section{Case 4}

A 30-year-old woman, was diagnosed with colonic Crohn's disease (Montreal Classification A2, L2, B1) in June 2013. On this occasion, she presented chronic diarrhea, abdominal pain, fever, weight loss, and painful erythematous skin lesions compatible with erythema nodosum. Laboratory exams showed an inflammatory process (CRP $6.8 \mathrm{mg} / \mathrm{dL}$, albumin 3.5 $\mathrm{g} / \mathrm{dL}$, hematocrit $41.3 \%$, hemoglobin $12.6 \mathrm{~g} / \mathrm{dL}$ ). The colonoscopy evidenced deep ulcers throughout the entire colon classified as disease in intense activity (Fig. 3). Prednisone 60 $\mathrm{mg} /$ day and azathioprine $(2 \mathrm{mg} / \mathrm{kg})$ were initiated. The patient presented significant im- 


\section{Case Reports in Gastroenterology}

Case Rep Gastroenterol 2018;12:608-616 DOI: 10.1159/000493921

(c) 2018 The Author(s). Published by S. Karger AG, Basel www.karger.com/crg

Silva et al.: Anti-TNF Exposure during Pregnancy in Crohn's Disease Patients

provement of symptoms and maintained an outpatient follow-up. In January 2014, the patient returned presenting bloody diarrhea 3 times a day, nausea, abdominal and epigastric pain, and malaise, characterizing moderate disease clinical activity, demanding corticosteroids (CRP $3.5 \mathrm{mg} / \mathrm{dl}$, albumin $3.6 \mathrm{~g} / \mathrm{dL}$ ). A colonoscopy performed in May 2014 showed active disease in the colon, rectum, and anal canal (Fig. 3). Due to the persistence of the clinical and endoscopic disease activity, adalimumab therapy was initiated in June 2014, combined with azathioprine. Approximately 30 days after starting the drug, the patient returned pregnant, showing improvement in intestinal symptoms. She suspended azathioprine use according to obstetric orientation. Adalimumab therapy was discontinued on the 24th gestational week. The patient remained in disease clinical remission and the baby was born in March 2015 by C-section.

\section{Discussion/Conclusion}

The IBD effect on pregnancy is largely attributed to the disease activity and to the collateral effects of medication [1]. A comprehensive meta-analysis of 12 studies including 3,907 IBD women compared to 320,531 controls showed an increase in preterm birth, low birth weight, congenital abnormalities, and C-section rates [3]. Regarding the cases presented, we observed one preterm birth and no low birth weight or congenital abnormalities. None of the mothers presented a history of miscarriage and all the babies were born by C-section. The high C-section rate was based on the women's preferences for delivery.

Disease activity is indicated as the main risk factor for negative outcomes during pregnancy [1]. Therefore, as the first recommendation, the patient should be in disease remission at conception, favoring a gestation with lower risks of gestational adversities [1]. Only one of the patients was in clinical and endoscopic remission at the time of conception. Despite this, the gestations occurred without complications.

IBD treatment should be maintained in patients who wish to become pregnant. Most medications offer a low risk to the fetus, except for methotrexate and thalidomide [1]. Aminosalicylates are considered low-risk medications, and folate supplementation should be considered for sulfasalazine-treated mothers [1]. The corticosteroids cross the placental barrier, but are readily converted into less active metabolites, resulting in low fetal blood levels. Some studies cite an orofacial malformation risk in fetuses whose mothers were exposed to corticosteroids in the first trimester of pregnancy, but the data are conflicting in the literature [4]. The antibiotics ciprofloxacin and metronidazole should be avoided in the first trimester due to fetal malformation risk [5]. Thiopurines, classified as Class D by the FDA, are shown to be safe when considering the infection risk acquired in the first years of life as well as considering their possible effect on the physical and mental development of the children [6].

Regarding biological therapy, studies have shown that anti-TNF agents are considered safe and do not increase the risk of adverse events during pregnancy [7], although the medication serum level can be detected for up to 6 months in the neonates of exposed mothers [8]. Therefore, live attenuated vaccines, such as rotavirus, oral polio, and BCG, are not indicated in immunosuppressed patients and should be postponed for 6 months or more in children exposed to anti-TNF agents in the gestational period $[1,8]$. Only one baby had the vaccines delayed. The other three babies received the vaccines according to the official calendar.

The Second European Consensus on Reproduction and Pregnancy in IBD states that there is no contraindication to infliximab use in pregnancy [1]. The medication crosses the placental barrier, especially in the third trimester [9]; therefore, it is recommended to interrupt the 


\section{Case Reports in Gastroenterology}

Case Rep Gastroenterol 2018;12:608-616 DOI: 10.1159/000493921

(c) 2018 The A www.karger.com/cr

Silva et al.: Anti-TNF Exposure during Pregnancy in Crohn's Disease Patients

treatment between the 24th and 26th week of gestation [1]. Adalimumab acts similarly to infliximab [8]. The anti-TNF agent serum level, both in the umbilical cord and in the newborn blood, may be high and can be detected until more than 6 months of life [8]. Despite this, there are few reports of side effects, including congenital malformation [10].

A prospective, multicenter study of 41 IBD carriers exposed to an anti-TNF agent (infliximab or adalimumab) showed no congenital malformation, and rates of miscarriage and low birth weight were the same as in the general population [11]. In this study, there was a higher frequency of preterm delivery (attributed to the underlying disease), but all occurred between 34 and 36 weeks of gestation with no perinatal complications during the first month of followup [11].

The major studies regarding infliximab use in Crohn's disease come from two main sources of registration: the Infliximab Safety Database [12] and Crohn's Therapy Resource Evaluation and Assessment Tool (TREAT) [13]. The Infliximab Safety Database consists of a retrospective database including 96 pregnant women exposed to infliximab for Crohn's disease or rheumatoid arthritis treatment. Of the 96 pregnancies evaluated, there were no fetal losses and only 2 cases of congenital anomaly occurred, a rate equal to the general population. In the prospective TREAT registry, 66 Crohn's disease pregnant women were reported, and 36 received infliximab during the pregnancy. There was no difference in the spontaneous abortion and neonatal complication rates among pregnant women who received or did not receive biological therapy and no fetal malformation was detected [13].

Data on vedolizumab safety in pregnancy is limited. There are documented cases of spontaneous abortions, and 1 case of congenital corpus callosum agenesis anomaly was reported in one live birth from a healthy volunteer exposed to a single dose of vedolizumab 79 days before conception [14]. No new safety concerns have been identified for pregnancy outcomes in females directly or indirectly exposed to vedolizumab. Vedolizumab should be used during pregnancy only if the benefits to the mother outweigh the risks to the mother and to the unborn child [14].

Regarding breastfeeding, some studies have detected insignificant drug serum levels in breast milk [15]. Lactation should always be stimulated and medications maintained, respecting individual recommendations for each drug.

We reported the management and evolution of 4 Crohn's disease patients who underwent biological therapy during pregnancy. In all cases, the gestation occurred without complications and the babies were born without complications. The data available so far point to inflammatory activity as the main risk factor for unfavorable gestational evolution and show that anti-TNF agents are safe during pregnancy and breastfeeding. Nevertheless, the benefits and risks must be discussed with the patient and management decisions should be taken on an individual basis.

\section{Acknowledgements}

We thank Botucatu Medical School at São Paulo State University (UNESP) for its support with this paper. 


\section{Statement of Ethics}

The study was approved by the Research Ethics Committee of Botucatu Medical School at São Paulo State University (protocol 1.809.851/2016).

\section{Disclosure Statement}

The authors have no conflicts of interest to declare.

\section{Funding Sources}

This research received no specific grant from any funding agency in the public, commercial, or not-for-profit sectors.

\section{Author Contributions}

All authors contributed to this manuscript. Elen Farinelli de Campos Silva, Júlio Pinheiro Baima, Jaqueline Ribeiro de Barros, and Ligia Yukie Sassaki contributed to the conception and design of the study, the acquisition, analysis, and interpretation of data, drafting the article, revising it critically for important intellectual content, and final approval of the version to be submitted. Fernanda Lofiego Renosto, Carina de Fatima de Sibia, and Rogério Saad-Hossne contributed to the acquisition, analysis, and interpretation of data and revising the article critically for important intellectual content.

\section{References}

1 van der Woude CJ, Ardizzone S, Bengtson MB, Fiorino G, Fraser G, Katsanos K, et al.; European Crohn's and Colitis Organization. The second European evidenced-based consensus on reproduction and pregnancy in inflammatory bowel disease. J Crohns Colitis. 2015 Feb;9(2):107-24.

2 Vermeire S, Carbonnel F, Coulie PG, Geenen V, Hazes JM, Masson PL, et al. Management of inflammatory bowel disease in pregnancy. J Crohns Colitis. 2012 Sep;6(8):811-23.

3 Cornish J, Tan E, Teare J, Teoh TG, Rai R, Clark SK, et al. A meta-analysis on the influence of inflammatory bowel disease on pregnancy. Gut. 2007 Jun;56(6):830-7.

4 McConnell RA, Mahadevan U. Pregnancy and the patient with Inflammatory Bowel Disease: fertility, treatment, delivery, and complications. Gastroenterol Clin North Am. 2016 Jun;45(2):285-301.

5 Gaidos JK, Kane SV. Managing IBD Therapies in pregnancy. Curr Treat Options Gastroenterol. 2017 Mar;15(1):71-83.

6 Huang VW, Chang HJ, Kroeker KI, et al. Management of inflammatory bowel disease during pregnancy and breastfeeding varies widely: a need for further education. Can J Gastroenterol Hepatol. 2016;2016:6193275.

7 Mahadevan U, McConnell RA, Chambers CD. Drug safety and risk of adverse outcomes for pregnant patients with Inflammatory Bowel Disease. Gastroenterology. 2017 Feb;152(2):451-462.e2.

8 Julsgaard M, Christensen LA, Gibson PR, Gearry RB, Fallingborg J, Hvas CL, et al. Concentrations of adalimumab and infliximab in mothers and newborns, and effects on infection. Gastroenterology. 2016 Jul;151(1):110-9.

9 Mahadevan U, Wolf DC, Dubinsky M, Cortot A, Lee SD, Siegel CA, et al. Placental transfer of anti-tumor necrosis factor agents in pregnant patients with inflammatory bowel disease. Clin Gastroenterol Hepatol. 2013 Mar;11(3):286-92.

10 Hoxha A, Calligaro A, Di Poi E, Peccatori S, Favaro M, Del Ross T, et al. Pregnancy and foetal outcomes following anti-tumor necrosis factor alpha therapy: A prospective multicentre study. Joint Bone Spine. 2017 Mar;84(2):169-73. 
Silva et al.: Anti-TNF Exposure during Pregnancy in Crohn's Disease Patients

11 Bortlik M, Machkova N, Duricova D, Malickova K, Hrdlicka L, Lukas M, et al. Pregnancy and newborn outcome of mothers with inflammatory bowel diseases exposed to anti-TNF- $\alpha$ therapy during pregnancy: three-center study. Scand J Gastroenterol. 2013 Aug;48(8):951-8.

12 Katz JA, Antoni C, Keenan GF, Smith DE, Jacobs SJ, Lichtenstein GR. Outcome of pregnancy in women receiving infliximab for the treatment of Crohn's disease and rheumatoid arthritis. Am J Gastroenterol. 2004 Dec;99(12):2385-92.

13 The Crohn's Therapy, Resource, Evaluation, and Assessment Tool Registry (TREAT). Janssen Biotech, Inc. Available from: https://clinicaltrials.gov/ct2/show/NCT00553176

14 Mahadevan U, Vermeire S, Lasch K, Abhyankar B, Bhayat F, Blake A, et al. Vedolizumab exposure in pregnancy: outcomes from clinical studies in inflammatory bowel disease. Aliment Pharmacol Ther. 2017 Apr;45(7):941-50.

15 Ben-Horin S, Yavzori M, Kopylov U, Picard O, Fudim E, Eliakim R, et al. Detection of infliximab in breast milk of nursing mothers with inflammatory bowel disease. J Crohns Colitis. 2011 Dec;5(6):555-8.
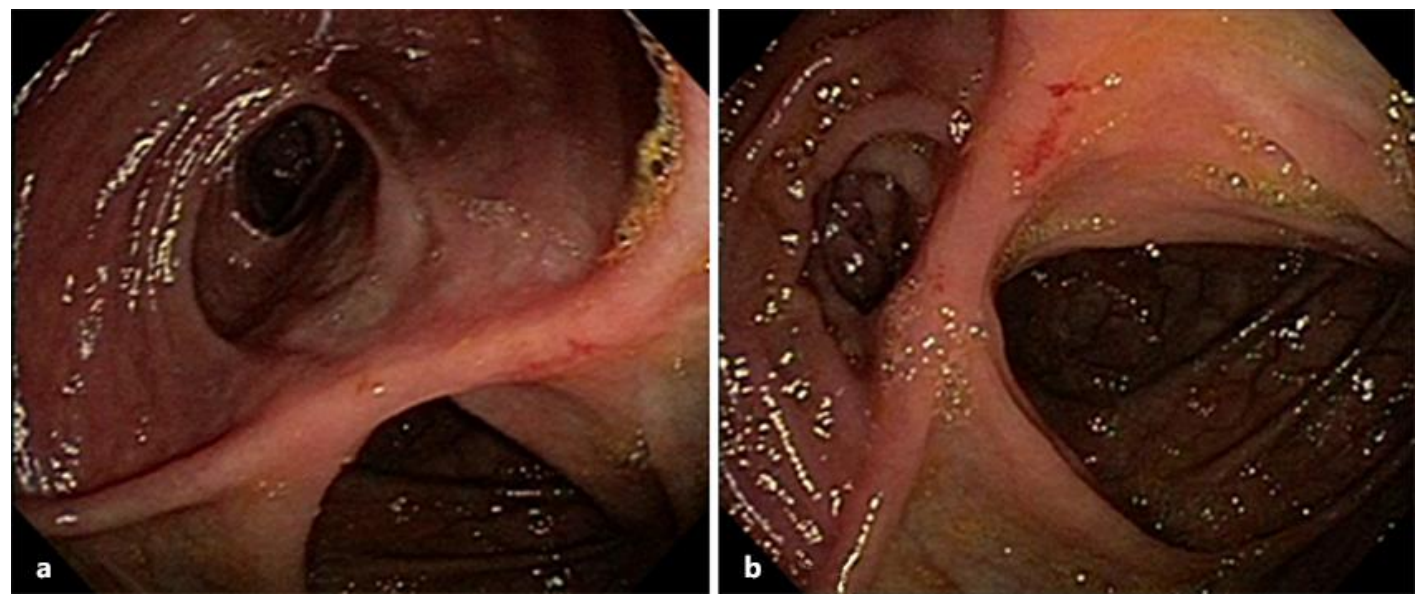

Fig. 1. Case 2. Colonoscopy showed no lesions in the neoterminal ileum or in the ileocolonic anastomosis (Rutgeerts score i0). 


\section{Case Reports in Gastroenterology}

\begin{tabular}{l|l}
\hline Case Rep Gastroenterol 2018;12:608-616 \\
\hline DOI: 10.1159/000493921 & $\begin{array}{l}\text { @ 2018 The Author(s). Published by S. Karger AG, Basel } \\
\text { www.karger.com/crg }\end{array}$ \\
\hline
\end{tabular}
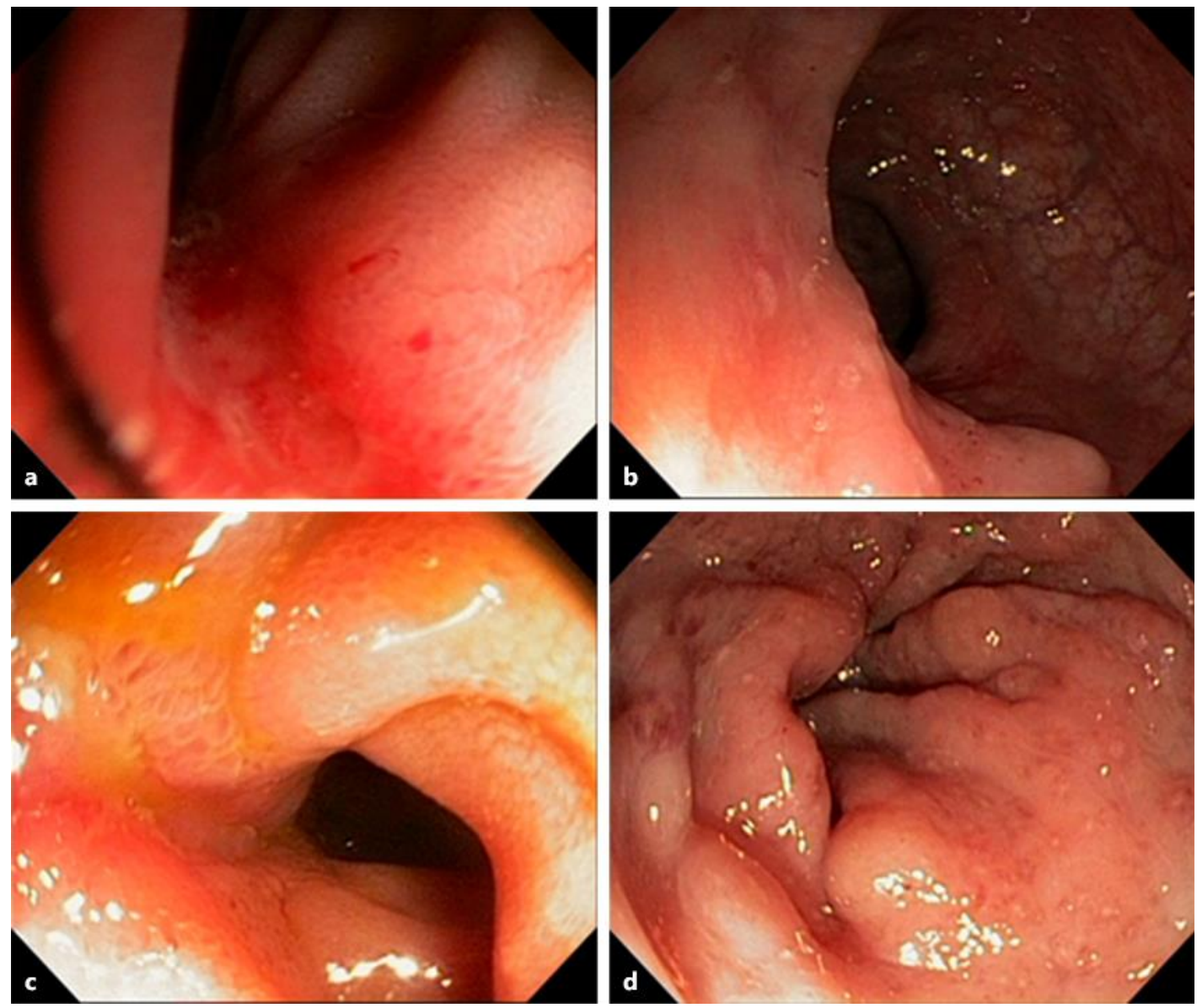

Fig. 2. Case 3. Colonoscopy performed in June 2013 showing inflammation in the terminal ileum (a) and erosions in the colon (b). Colonoscopy performed in June 2014 showing a linear ulcer in the distal ileum (c) and erosions in the sigmoid and rectum (d). 


\section{Case Reports in Gastroenterology}

\begin{tabular}{l|l}
\hline Case Rep Gastroenterol 2018;12:608-616 \\
\hline DOI: 10.1159/000493921 & $\begin{array}{l}\text { @ 2018 The Author(s). Published by S. Karger AG, Basel } \\
\text { www.karger.com/crg }\end{array}$ \\
\hline
\end{tabular}
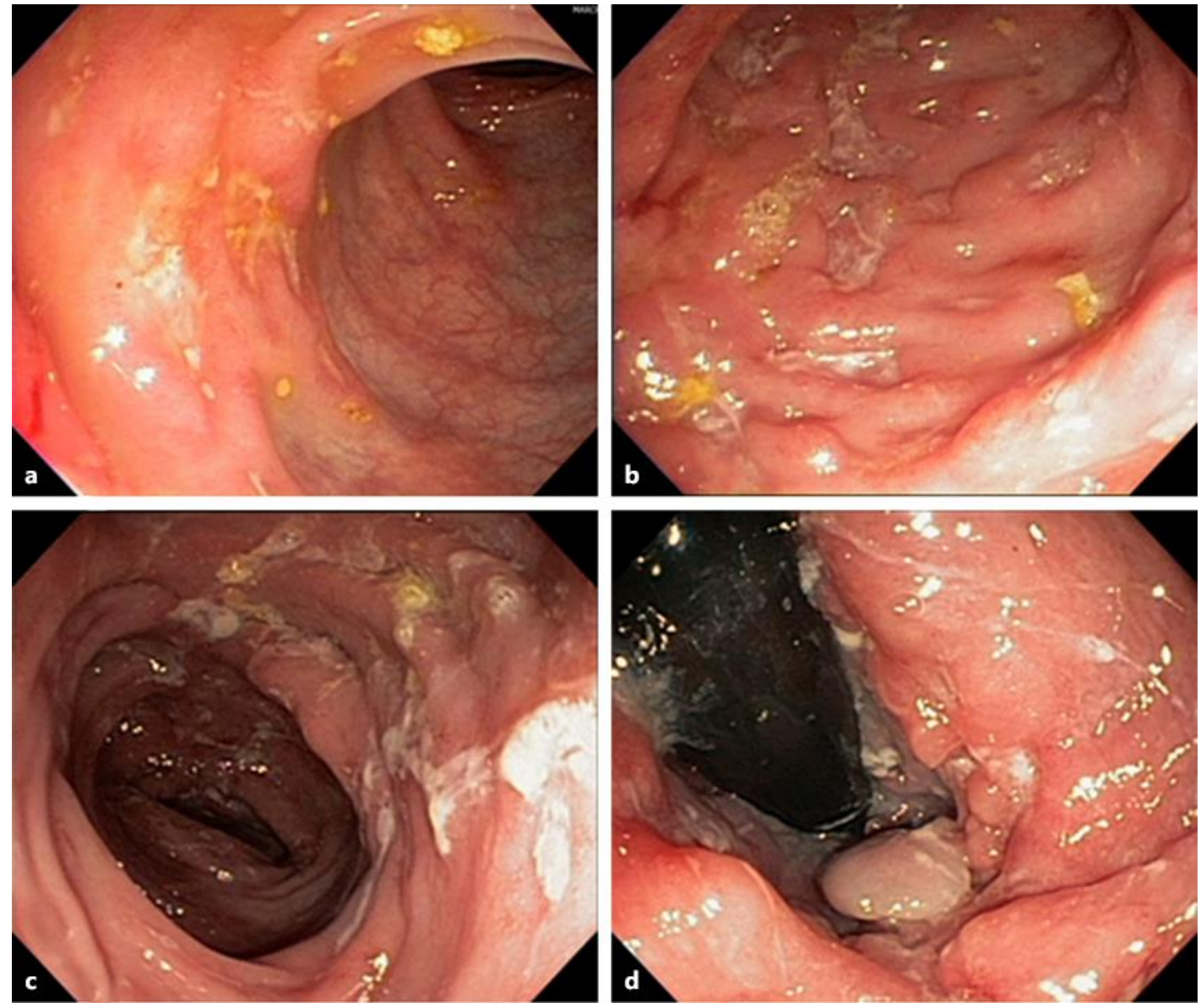

Fig. 3. Case 4. Colonoscopy performed in June 2013 evidenced deep ulcers throughout the entire colon classified as disease in intense activity (a, b). Colonoscopy performed in May 2014 showed active disease in the colon and rectum $(\mathbf{c}, \mathbf{d})$. 